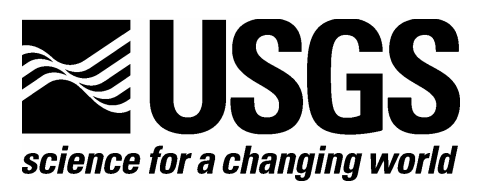

In Cooperation with the Maine Department of Environmental Protection

\title{
Pilot Study of Sublethal Effects on Fish of Pesticides Currently Used and Proposed for Use on Maine Blueberries
}

By Adria A. Elskus

Open-File Report 2007-1110 


\section{U.S. Department of the Interior DIRK KEMPTHORNE, Secretary}

\section{U.S. Geological Survey \\ Mark D. Myers, Director}

U.S. Geological Survey, Reston, Virginia: 2007

For product and ordering information:

World Wide Web: http://www.usgs.gov/pubprod

Telephone: 1-888-ASK-USGS

For more information on the USGS - the Federal source for science about the Earth, its natural and living resources, natural hazards, and the environment:

World Wide Web: http://www.usgs.gov

Telephone: 1-888-ASK-USGS

Suggested citation:

Elskus, A.A., 2007, Pilot study of sublethal effects on fish of pesticides currently used and proposed for use on Maine blueberries: U.S. Geological Survey Open-File Report 2007-1110, 10 p.

Any use of trade, product, or firm names is for descriptive purposes only and does not imply endorsement by the U.S. Government.

Although this report is in the public domain, permission must be secured from the individual copyright owners to reproduce any copyrighted material contained within this report. 


\section{Contents}

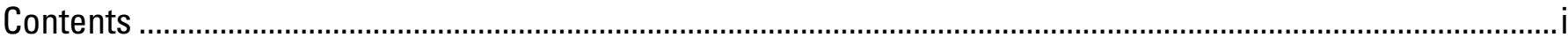

Conversion Factors and Abbreviations ............................................................................................................

Abstract

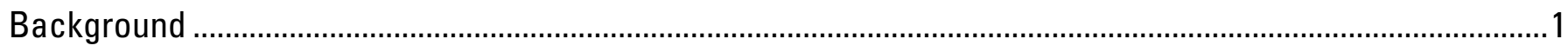

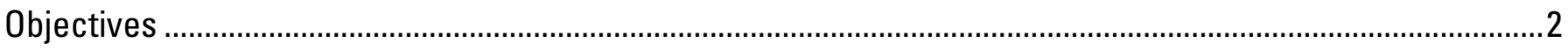

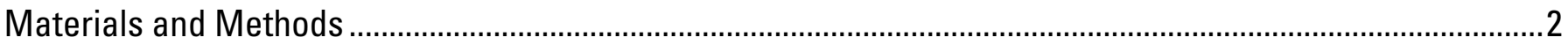

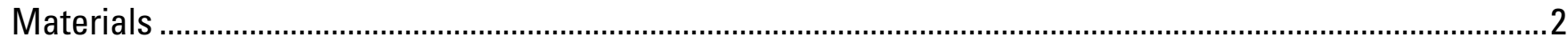

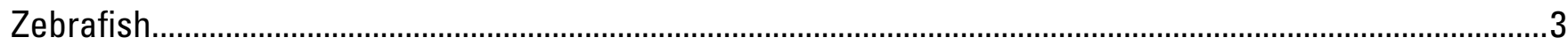

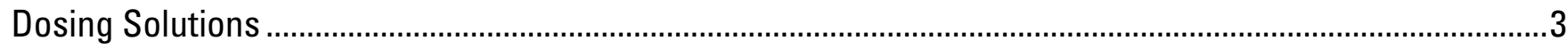

Confirmation of Pesticide Dosing Concentrations............................................................................................

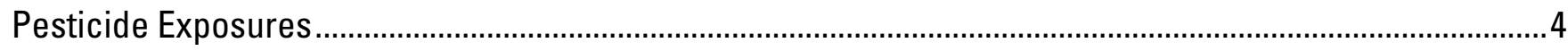

Mortality, Time to Hatch, Developmental Abnormalities ..............................................................................

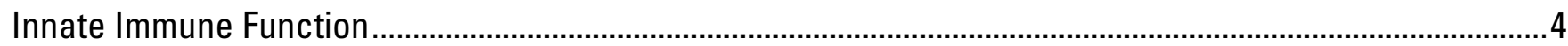

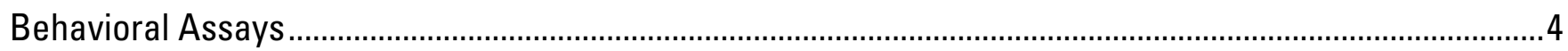

Results of Preliminary Studies on the Effects of Blueberry Pesticides on Fish................................................

Dosing Solution Concentrations …………………………………………………………………....

Innate Immune Function .....................................................................................................................

Mortality, Time to Hatch, Developmental Abnormalities ..............................................................................

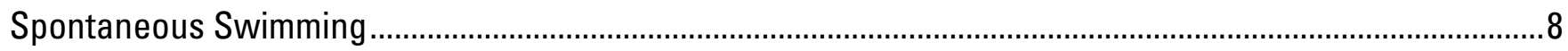

Conclusions and Additional Research............................................................................................

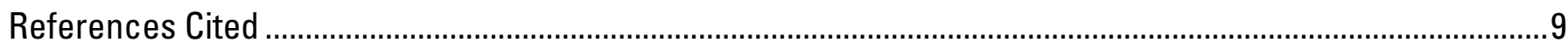

\section{Figures}

1-4. Graphs showing-

1. Preliminary data on the effects of exposure to single pesticide formulations on the innate immune system of zebrafish embryo-larvae exposed from fertilization through swim-up larvae

2. Preliminary data on the effects of exposure to single pesticide formulations on the innate immune system of zebrafish embryo-larvae exposed from fertilization through the swim-up larval stage

3. Preliminary data on the effects of exposure to mixtures of pesticide formulations on the innate immune system of zebrafish embryo-larvae exposed from fertilization through the swim-up larval stage.

4. Preliminary data on single pesticide exposure effects on spontaneous swimming in zebrafish exposed from fertilization through swim-up

\section{Tables}

1. Preliminary analyses demonstrating that nominal and actual dosing solutions concentrations are similar.

2. Mean days to hatch for zebrafish exposed to pesticide formulations from fertilization through swim-up larvae. 


\section{Conversion Factors and Abbreviations}

\section{SI to Inch/Pound}

\begin{tabular}{|c|c|c|}
\hline Multiply & By & To obtain \\
\hline \multicolumn{3}{|c|}{ Length } \\
\hline centimeter $(\mathrm{cm})$ & 0.3937 & inch (in.) \\
\hline millimeter (mm) & 0.03937 & inch (in.) \\
\hline \multicolumn{3}{|c|}{ Area } \\
\hline square centimeter $\left(\mathrm{cm}^{2}\right)$ & 0.001076 & square foot $\left(\mathrm{ft}^{2}\right)$ \\
\hline square centimeter $\left(\mathrm{cm}^{2}\right)$ & 0.1550 & square inch $\left(\mathrm{ft}^{2}\right)$ \\
\hline \multicolumn{3}{|c|}{ Volume } \\
\hline liter (L) & 33.82 & ounce, fluid (fl. oz) \\
\hline liter (L) & 2.113 & pint (pt) \\
\hline liter (L) & 1.057 & quart (qt) \\
\hline liter (L) & 0.2642 & gallon (gal) \\
\hline liter $(\mathrm{L})$ & 61.02 & cubic inch $\left(\mathrm{in}^{3}\right)$ \\
\hline \multicolumn{3}{|c|}{ Flow rate } \\
\hline milliliter per minute $(\mathrm{mL} / \mathrm{min})$ & 0.0002642 & gallon per minute (gal/min) \\
\hline & Mass & \\
\hline milligram (mg) & 0.00003527 & ounce, avoirdupois (oz) \\
\hline \multicolumn{3}{|c|}{ Pressure } \\
\hline kilopascal (kPa) & 0.009869 & atmosphere, standard (atm) \\
\hline kilopascal (kPa) & 0.01 & bar \\
\hline kilopascal (kPa) & 0.1450 & pound-force per inch (lbf/in) \\
\hline kilopascal (kPa) & 20.88 & pound per square foot $\left(\mathrm{lb} / \mathrm{ft}^{2}\right)$ \\
\hline kilopascal (kPa) & 0.1450 & pound per square inch $\left(\mathrm{lb} / \mathrm{ft}^{2}\right)$ \\
\hline
\end{tabular}

Temperature in degrees Celsius $\left({ }^{\circ} \mathrm{C}\right)$ may be converted to degrees Fahrenheit $\left({ }^{\circ} \mathrm{F}\right)$ as follows: ${ }^{\circ} \mathrm{F}=\left(1.8 \mathrm{x}^{\circ} \mathrm{C}\right)+32$

Temperature in degrees Fahrenheit $\left({ }^{\circ} \mathrm{F}\right)$ may be converted to degrees Celsius $\left({ }^{\circ} \mathrm{C}\right)$ as follows: ${ }^{\circ} \mathrm{C}=\left({ }^{\circ} \mathrm{F}-32\right) / 1.8$

\section{Abbreviations:}

ng, nanogram

nm, nanometer

$\mathrm{mL}$, milliliter

$\mu \mathrm{L}$, microliter

$\mathrm{ppb}$, parts per billion

uv, ultraviolet 


\title{
Pilot Study of Sublethal Effects on Fish of Pesticides Currently Used and Proposed for Use on Maine Blueberries
}

\author{
By Adria A. Elskus
}

\section{Abstract}

Blueberry pesticides have been detected consistently in some Down East Maine rivers, yet little is known about the sublethal effects of these pesticides on fish early life stages. The Maine blueberry industry is proposing to replace the insecticide $\operatorname{Imidan}^{\mathrm{TM}}$ (active ingredient phosmet) and the herbicide $\operatorname{Velpar}^{\mathrm{TM}}$ (active ingredient hexazinone), two of the pesticides found in these rivers, with candidate alternatives SpinTor ${ }^{\mathrm{TM}}$ (active ingredient spinosad) and Callistso ${ }^{\mathrm{TM}}$ (active ingredient mesotrione). Our objective is to evaluate potential sublethal effects of these four formulations before the industry adopts the two candidate alternatives. We exposed zebrafish (Danio rerio) early life stages, from fertilization through larval swim-up, to a range of pesticide concentrations and evaluated their response relative to untreated controls. In this report we provide preliminary data on immune function as well as on parameters in addition to those originally proposed: development and performance fitness. We also provide information on our progress towards optimizing chemical protocols for analyzing the concentration of active ingredient in each of our formulation dosing solutions, another new parameter we added to those originally proposed. Preliminary results indicate that at environmentally realistic concentrations, these pesticides may have no significant effect on innate immunity, development rate or behavior (spontaneous swimming), however further replication is needed to confirm these initial findings. We have also observed some degree of developmental abnormalities in both pesticide-treated and control zebrafish embryos; however, additional replication is underway to determine if these groups differ significantly.

\section{Background}

Dramatic declines in Atlantic salmon (Salmo salar) populations in the northeastern U.S. have led to the complete loss of wild salmon in all New England states except for eight rivers in Maine where Atlantic salmon are now listed as an endangered distinct population segment (DPS) (National Research Council, 2004). Despite intensive efforts to restore Maine populations through juvenile stocking programs, adult returns continue to be well below the estimated carrying capacities of these rivers (Maine Atlantic Salmon Task Force, 1997).

The Maine Board of Pesticide Control has consistently detected blueberry pesticides, including phosmet and hexazinone, in certain DPS rivers (Jackson, 2003). With little to no data on the relative risk to salmon health posed by blueberry pesticides, restoration managers cannot rule out the possibility that these pesticides are hampering recovery and restoration efforts for endangered Maine Atlantic salmon.

Early life stages are considered the most sensitive to stressors, and because biochemical, hormonal and morphological changes that occur during early development are irreversible, toxicant 
exposure during early life is almost certain to have permanent effects on populations (Lawrence and Hemingway, 2003). Indeed, developmental exposure to atrazine, a triazine related to hexazinone, produced altered immune function in adulthood (Rooney and others, 2003). Moreover, a broad range of species may be affected since pesticides, including organophosphates and triazines, deleteriously affect immune function in a wide range of invertebrate and vertebrate species (Dunier, 1996; Galloway and others, 2003).

Many pesticides exert their toxicity during metabolism and do not accumulate in biological tissues, including the pesticides being evaluated in the current study. Consequently, body burden analysis, as is done in many government-funded monitoring programs to evaluate the effect of persistent organic contaminants, will not reflect pesticide exposure or effect. Instead what is necessary is to characterize the exposure regime and define effect levels in carefully controlled exposure studies.

For this pilot study, the U.S. Geological Survey, in cooperation with the Maine Department of Environmental Protection, used zebrafish, a well-characterized aquatic toxicology model for which a sensitive assay of immune system function has recently been developed (Hermann and others, 2004), whose development is well-documented (Westerfield, 1993) and for which behavioral assays have been published (Samson and others, 2001). This paper presents the preliminary results of this study.

\section{Objectives}

The original objectives of this study were to:

1. Evaluate the immunotoxic effects on fish early life stages of two currently used blueberry pesticides, phosmet and hexazinone, consistently detected in Maine Down East rivers.

2. Evaluate the immunotoxic effects of the proposed alternative pesticides, spinosad and mesotrione.

3. Determine whether pesticide mixtures reflective of those observed for currently used pesticides in Maine Down East rivers have additive, synergistic, or antagonistic effects on immune function.

4. Provide preliminary information to the Maine Board of Pesticide Control regarding the sublethal effects of candidate pesticides on fish before they are adopted by Maine blueberry growers.

Additional objectives subsequently incorporated into this study were to:

5. Evaluate developmental and behavioral effects on fish early life stages of two currently used pesticides, phosmet and hexazinone, and their proposed alternatives, spinosad and mesotrione.

6. Develop and optimize analytical protocols for measuring aqueous concentrations of the currently used pesticides, phosmet and hexazinone, and their proposed alternatives, spinosad and mesotrione.

\section{Materials and Methods}

The materials and methods used during the course of this pilot study are presented below.

\section{Materials}

Pesticide formulations Imidan $^{\mathrm{TM}}$ (Gowan), Velpar-L ${ }^{\mathrm{TM}}$ (DuPont), Callisto ${ }^{\mathrm{TM}}$ (Syngenta), and SpinTor $^{\mathrm{TM}}$ (Dow AgroSciences) were obtained from the University of Maine Blueberry Extension Office, courtesy of Dr. Frank Drummond. Styrene-divinylbenzene (SDB-L) solid phase extraction 
(SPE) columns (500 mg/6 mL) were obtained from Phenomenex (Torrance, Cal.). Solvents were high purity pesticide grade from Fisher Scientific, Inc Pittsburgh, PA. Dihydrodichlorofluorescein diacetate $\left(\mathrm{H}_{2} \mathrm{DCFDA}\right)$ was from Invitrogen (Carlsbad, Cal.), phorbol 12-myristate 13-acetate (PMA) and black 96 well plates were from Fisher Scientific, Inc. (Pittsburgh, Pa.). Pesticide standards were obtained from the U. S. Environmental Protection Agency's (USEPA) National Pesticide Standard Repository (Fort Meade, Md.).

\section{Zebrafish}

Zebrafish embryos (AB strain) were obtained from the University of Maine's Zebrafish Core (University of Maine, 2007). Tanks of 14 females and 12 males were spawned as needed to provide these fish.

\section{Dosing Solutions}

Dosing concentrations were based on pesticide levels reported in the Pleasant River by the Maine Board of Pesticide Control for hexazinone and phosmet (Jackson, 2003). Velpar ${ }^{\mathrm{TM}}$, Imidan $^{\mathrm{TM}}$, Callisto ${ }^{\mathrm{TM}}$, and SpinTor ${ }^{\mathrm{TM}}$ stock solutions were prepared in egg water and diluted to the desired concentrations. Solution concentrations were based on the concentration of active ingredient in the formulation. To determine whether pesticide mixtures measured in the Down East rivers of Maine have additive, synergistic, or antagonistic effects, we exposed embryos to single formulations and to mixtures $\left(\operatorname{Velpar}^{\mathrm{TM}}+\operatorname{Imidan}^{\mathrm{TM}}\right.$, Callisto $^{\mathrm{TM}}+\operatorname{SpinTor}^{\mathrm{TM}}$ ), in combinations and concentrations measured in the Down East rivers of Maine for phosmet+hexazinone $(0.2,0.75,2.0$, $3.0 \mathrm{ppb}$, (Jackson, 2003) and doses 10 times as high (7.5, $30 \mathrm{ppb})$. Pesticide solutions were prepared within 2 to $3 \mathrm{~h}$ (hours) of the start of the experiment and then held at $28{ }^{\circ} \mathrm{C}$ in the incubators with the fish on a 14-h/10-h light/dark cycle to mimic conditions under which singleapplication pesticide exposures 'age' in the field. To prevent the buildup of ammonia in the exposure plates, treatment water was replaced daily using the incubator-held dosing solutions.

\section{Confirmation of Pesticide Dosing Concentrations}

To determine if nominal dosing concentrations reflect actual dosing concentrations, we are optimizing protocols for analyzing the concentration of active ingredients in our dosing solutions at the start and conclusion of the 5-d (day) exposure periods. While protocols for extracting phosmet and hexazinone from river water have been established (L.B. Perkins, University of Maine, oral comm.), there are few protocols for the candidate pesticides, mesotrione and spinosad. With guidance from Dr. L. Brian Perkins (University of Maine) and Dr. Larry LeBlanc (University of Maine) we have conducted preliminary experiments evaluating the utility of styrene divinylbenzene-coated silica gel (SDB-L) solid phase extraction (SPE) cartridges to capture mesotrione and spinosad from aqueous solutions of Callisto ${ }^{\mathrm{TM}}$ and SpinTor ${ }^{\mathrm{TM}}$, respectively, and confirmed and optimized the ability of this cartridge packing to capture hexazinone and phosmet from aqueous solutions of $\operatorname{Velpar}^{\mathrm{TM}}$ and $\operatorname{Imidan}^{\mathrm{TM}}$, respectively. Dr. L. Brian Perkins (University of Maine) is working with us to optimize analysis conditions for spinosad and mesotrione by high performance liquid chromatography (HPLC). Briefly, 500- to 1,000-mL pesticide dosing solutions (Velpar $^{\mathrm{TM}}$, Imidan $^{\mathrm{TM}}$, Callisto ${ }^{\mathrm{TM}}$, SpinTor ${ }^{\mathrm{TM}}$ ) were pulled through SBD-L SPE cartridges under vacuum $(25 \mathrm{kPa})$, the cartridges eluted with acetonitrile $\left(\right.$ Callisto ${ }^{\mathrm{TM}}$, SpinTor $^{\mathrm{TM}}$ for meotrione, spinosad) or ethyl acetate (Velpar ${ }^{\mathrm{TM}}, \operatorname{Imidan}^{\mathrm{TM}}$ for hexazinone, phosmet) and two fractions collected $(1 \mathrm{~mL}, \mathrm{~F} 1 ; 5 \mathrm{~mL}, \mathrm{~F} 2)$. Eluates for $\operatorname{Velpar}^{\mathrm{TM}}$ and Imidan $^{\mathrm{TM}}$ were dried over sodium sulfate (baked at $600{ }^{\circ} \mathrm{C}$ for $12 \mathrm{~h}$ ), volume reduced to $900 \mu \mathrm{L}$, spiked with $100 \mu \mathrm{L}$ of chlorpyrifos $(10 \mathrm{ng} / \mu \mathrm{L})$ as an internal standard, and injected onto a Hewlett Packard 5890/5870 gas chromatograph-mass spectrometry (GC/MS) system $(2 \mu \mathrm{L}$, splitless), with helium as the carrier gas, under the following conditions: $275^{\circ} \mathrm{C}$ injection port, ramping from $80{ }^{\circ} \mathrm{C}-250{ }^{\circ} \mathrm{C}$ at $20^{\circ} \mathrm{C} / \mathrm{min}$ (minute), $1.2 \mathrm{~mL} / \mathrm{min}$ 
flow rate. Full scan mode was used to identify the quantification ions and qualifying ions for hexazinone, phosmet, chlorpyrifos (a surrogate for phosmet), and metribuzin (a surrogate for hexazinone). Eluates for Callisto ${ }^{\mathrm{TM}}$ and SpinTor ${ }^{\mathrm{TM}}$ were dried over sodium sulfate, volume reduced under high purity nitrogen to $1 \mathrm{~mL}$, and injected $(20 \mu \mathrm{L})$ onto a Hewlett Packard High Performance Liquid Chromatograph Series 1050 fitted with a C-18 column (100 x $4.6 \mathrm{~mm})$. We used a mobile phase of 75 percent ACN, 25 percent water, a flow rate of $1 \mathrm{~mL} / \mathrm{min}$, and monitored the analytes spinodad and mestrione at a wavelength of $271 \mathrm{~nm}$. This wavelength was determined to provide the maximum signal by performing a full-UV scan of each analyte using diode-array UV detection.

\section{Pesticide Exposures}

Zebrafish embryos were exposed to pesticides or egg water (0.6-percent Instant Ocean prepared in nanopure water) for 5 days in 100-mm diameter plastic petri dishes (40-50 embryos/dish) at $28{ }^{\circ} \mathrm{C}$ on a 14-h/10-h light/dark cycle from 2 to $3 \mathrm{~h}$ post-fertilization (Day 0) to $120 \mathrm{~h}$ post-fertilization (Day 4), an age where they display immunologic competence (Hermann and others, 2004). Treatment water in the petri dishes was renewed daily. For the immune system assays, experiments were terminated on Day 4 (120 h post-fertilization). For developmental and behavioral studies, zebrafish were transferred on Day 4 from the petri dish pesticide exposures to clean egg water in $250-\mathrm{mL}$ beakers suspended in flow-through tanks at $28^{\circ} \mathrm{C}$. Zebrafish larvae were held in the flow-through system through the end of the experiment (Day 7) with daily feedings of rotifers or dry food once per day on Days 5 to 7 . Each replicate experiment used embryos from a different spawn.

\section{Mortality, Time to Hatch, Developmental Abnormalities}

Zebrafish embryos were monitored daily from fertilization through the end of each experiment for mortality, days to hatch, and evidence of developmental abnormalities.

\section{Innate Immune Function}

We evaluated respiratory burst, a simple immune system assay, as described by Herman and others (2004)). Briefly, on Day 4 zebrafish larvae were transferred from exposure dishes to black 96 well plates, one larva per well, and exposed to either substrate alone ( $\mathrm{H}_{2}$ DCFDA, 6 wells) or substrate plus phorbol 12-myristate 13-acetate (PMA) (6 wells). PMA provokes the production of superoxide. In turn, superoxide oxidizes the substrate $\mathrm{H}_{2}$ DCFDA (a non-fluorescent dye) to dichlorofluorescein (DCF, a fluorescent product). In fish with a healthy immune system, PMA exposure in the presence of $\mathrm{H}_{2}$ DCFDA will provoke substantial production of DCF. PMA thus serves both as the stimulant and as a positive control to confirm the assay is working properly. Evolution of DCF was monitored for up to $3.5 \mathrm{~h}$ in a Perkin Elmer Fusion ${ }^{\mathrm{TM}}$ fluorescence plate reader at an excitation/emission of $485 \mathrm{~nm} / 530 \mathrm{~nm}$.

\section{Behavioral Assays}

We evaluated spontaneous swimming using the protocol described by Samson and others (2001). Briefly, larvae were placed individually into $100 \mathrm{~mL}$ of egg water in an 8-cm-diameter finger bowl placed over a $1-\mathrm{cm}^{2}$ grid. After a 2-min acclimation period, the number of lines crossed in $30 \mathrm{sec}$ (seconds) by the larvae was recorded. Five random larvae were tested from each replicate for each treatment on Days 4 and 7 post-fertilization. A second behavioral assay, prey capture, a well-established measure of performance fitness in fish (Samson and others, 2001) is currently underway. 


\section{Results of Preliminary Studies on the Effects of Blueberry Pesticides on Fish}

A discussion of preliminary study results follows and includes a presentation of dosing solution concentrations, innate immune function, mortality, time to hatch, developmental abnormalities, and spontaneous swimming.

\section{Dosing Solution Concentrations}

Pesticide standards were readily detectable by GC/MS (hexazinone and phosmet), and by HPLC (spinosad, mesotrione). Surrogates for phosmet (chlorpyrifos) and hexazinone (metribuzin) were also easily detected by GC/MS. We are currently in the process of obtaining surrogates for spinosad (spinetoram) and mesotrione (sulcotrione) from the manufacturers as they are not available from the USEPA National Pesticide Repository. These surrogates will be used to spike the dosing solutions prior to extraction through SPEs and, with internal standard spikes, will be used to correct for analyte recovery.

Preliminary analyses of the pesticide dosing solutions indicate that the actual (measured) concentrations are close to nominal concentrations for $\operatorname{Imidan}^{\mathrm{TM}}$ and $\operatorname{Velpar}^{\mathrm{TM}}$ (table 1).

Table 1. Preliminary analyses demonstrating that nominal and actual dosing solutions concentrations are similar.

[ppb, parts per billion]

\begin{tabular}{|c|c|c|c|c|}
\hline Dosing Formulation & Dose & Active Ingredients & Nominal (ppb) & Actual (ppb) \\
\hline \multirow[t]{4}{*}{ Velpar $^{\mathrm{TM}}$ plus Imidan $^{\mathrm{TM}}$} & Low & hexazinone & 0.75 & 0.35 \\
\hline & & phosmet & 0.75 & 0.21 \\
\hline & High & hexazinone & 7.50 & 5.6 \\
\hline & & phosmet & 7.50 & 5.0 \\
\hline
\end{tabular}

\section{Innate Immune Function}

We found no consistent effects of the blueberry pesticide formulations on the innate immune function of developing zebrafish. The results of initial experiments with exposure to single pesticide formulations over a wide range of doses, from environmentally relevant (0.2-3.0 $\mathrm{ppb})$ to 10 times as high $(7.5,30 \mathrm{ppb})$, indicated there were no effects of any of the formulations on the respiratory burst response of embryo-larval zebrafish (fig. 1). In these initial experiments, the zebrafish response was monitored for $2 \mathrm{~h}$. 


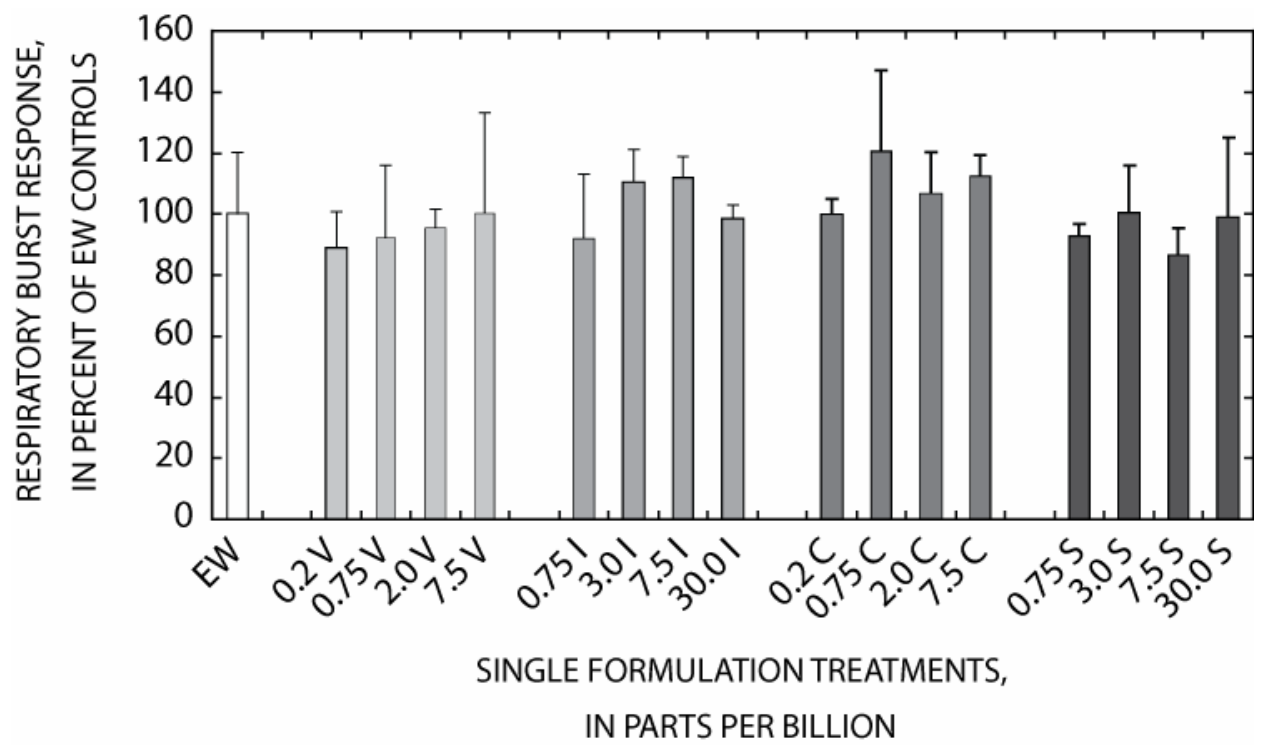

Figure 1. Preliminary data on the effects of exposure to single pesticide formulations on the innate immune system of zebrafish embryo-larvae exposed from fertilization through swim-up larvae. Bars represent means $\pm S D$ for $n=2-4$ replicates of 6 larvae per replicate. $E W=E g g$ Water, $V=V_{\text {elpar }}{ }^{\mathrm{TM}}, I=$ Imidan $^{\mathrm{TM}}, \mathrm{C}=$ Callisto $^{\mathrm{TM}}, \mathrm{S}=\mathrm{SpinTor}{ }^{\mathrm{T} \mathrm{M}}$. Doses were $0.2,0.75,2.0,3.0,7.5$, and 30 ppb. Respiratory burst was measured for 2 hours.

To improve and optimize the sensitivity of the assay, we extended the monitoring time to $3.5 \mathrm{~h}$. However, even with the improved signal strength afforded by the longer monitoring duration, there appear to be no effects of these pesticide formulations on zebrafish respiratory burst (fig. 2).

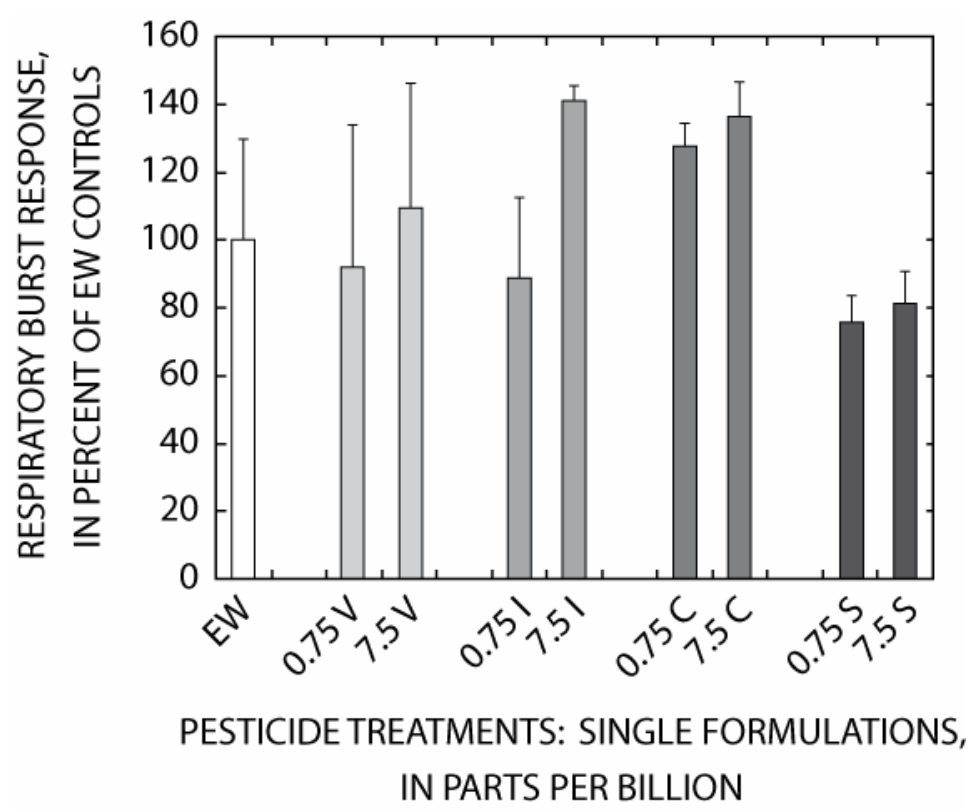

Figure 2. Preliminary data on the effects of exposure to single pesticide formulations on the innate immune system of zebrafish embryo-larvae exposed from fertilization through the swim-up larval stage. Bars represent means $\pm S D$ for $n=2-4$ replicates of 6 larvae per replicate. $E W=E g g$ Water, $\mathrm{V}=\mathrm{Velpar}^{\mathrm{TM}}, \mathrm{I}=\operatorname{Imidan}^{\mathrm{TM}}, \mathrm{C}=$ Callisto $^{\mathrm{TM}}, \mathrm{S}=\mathrm{SpinTor}^{\mathrm{TM}}$. Doses were 0.75 and $7.5 \mathrm{ppb}$. Respiratory burst was measured for 3.5 hours. 
Due to ground-water contamination in the watershed, hexazinone is present year-round in the Pleasant River, one of the salmon rivers in Down East Maine, and thus is present in July when the insecticide Imidan ${ }^{\mathrm{TM}}$ (phosmet) is applied. To determine if pesticide mixtures have additive, synergistic, or antagonistic effects, we looked at pesticide mixtures at a variety of doses.

Preliminary results (for one replicate per mixture) indicate mixtures do not affect the respiratory burst response of developing zebrafish (fig. 3); however, further replication is needed before firm conclusions can be made.

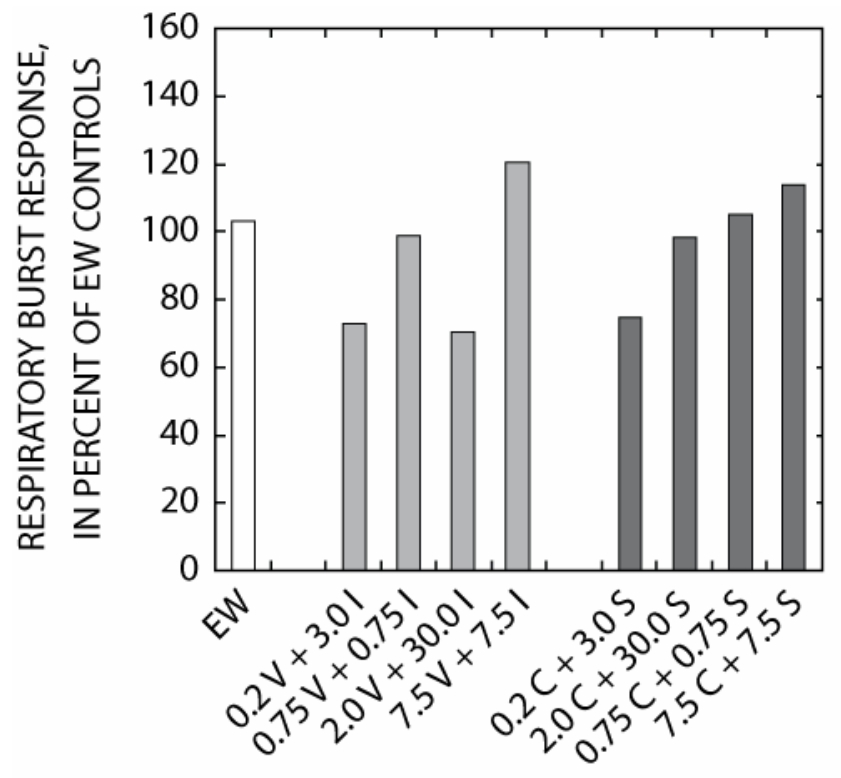

PESTICIDE TREATMENTS: FORMULATION MIXTURES, IN PARTS PER BILLION

Figure 3. Preliminary data on the effects of exposure to mixtures of pesticide formulations on the innate immune system of zebrafish embryo-larvae exposed from fertilization through the swim-up larval stage. Bars represent means for one replicate, 6 larvae per replicate. EW=Egg Water, $\mathrm{V}=$ Velpar $^{\mathrm{TM}}, \mathrm{I}=\operatorname{Imidan}^{\mathrm{TM}}, \mathrm{C}=$ Callisto $^{\mathrm{TM}}, \mathrm{S}=$ SpinTor $^{\mathrm{TM}}$. Doses were combinations of $0.2,0.75,2.0,3.0$, 7.5 , and $30 \mathrm{ppb}$. Respiratory burst was measured for 3.5 hours.

\section{Mortality, Time to Hatch, Developmental Abnormalities}

Zebrafish embryo mortality is typically 20 to 50 percent within the first 24 h postfertilization (M. Nilan, University of Maine, oral commun., 2007). We found similar rates of mortality in our exposures, with no difference among treatments (data not shown).

We observed evidence of developmental abnormalities in the pesticide treated groups, with very few occurrences in the controls. These abnormalities included reduced growth, small head with small or no eyes, pericardial edema, and scoliosis. A few individuals were moribund. All individuals displaying these abnormalities failed to hatch. These data will be recorded quantitatively in future exposures.

Despite evidence of abnormal development, preliminary data indicate no significant difference in developmental rate $(\mathrm{P}<0.05$, two-tailed Student's t-test $)$ as measured by the mean number of days it took the embryos to hatch (table 2). 
Table 2. Mean days to hatch for zebrafish exposed to pesticide formulations from fertilization through swim-up larvae. Mean \pm SD for $n=3$ replicates of 50 embryos per replicate.

[n, number; ppb, parts per billion; SD, Standard Deviation]

\begin{tabular}{llcc}
\hline \multicolumn{1}{c}{ Treatment } & Dose (ppb) & Mean days to hatch & SD \\
\hline Egg water control & 0 & 2.90 & 0.33 \\
Velpar $^{\mathrm{TM}}$ & 0.75 & 2.95 & 0.56 \\
& 7.5 & 3.08 & 0.42 \\
Imidan $^{\mathrm{TM}}$ & 0.75 & 3.42 & 0.11 \\
& 7.5 & 3.18 & 0.20 \\
Callisto $^{\mathrm{TM}}$ & 0.75 & 3.36 & 0.71 \\
& 7.5 & 3.18 & 0.54 \\
SpinTor $^{\mathrm{TM}}$ & 0.75 & 2.89 & 0.26 \\
& 7.5 & 3.11 & 0.22 \\
\hline
\end{tabular}

\section{Spontaneous Swimming}

Preliminary data on the effects of pesticide exposure on spontaneous swimming show no definitive trend (fig. 4). The large variability in these data reflect the small sample size $(n=2)$. Further experiments replicating this endpoint are underway to reduce this variability. Swimming activity and the ability to capture prey are related behaviors, which together provide a measure of performance fitness. Ongoing experiments evaluating prey capture in dosed zebrafish will be related to our results with spontaneous swimming to determine if alterations in prey capture may be related to alterations in swimming activity.

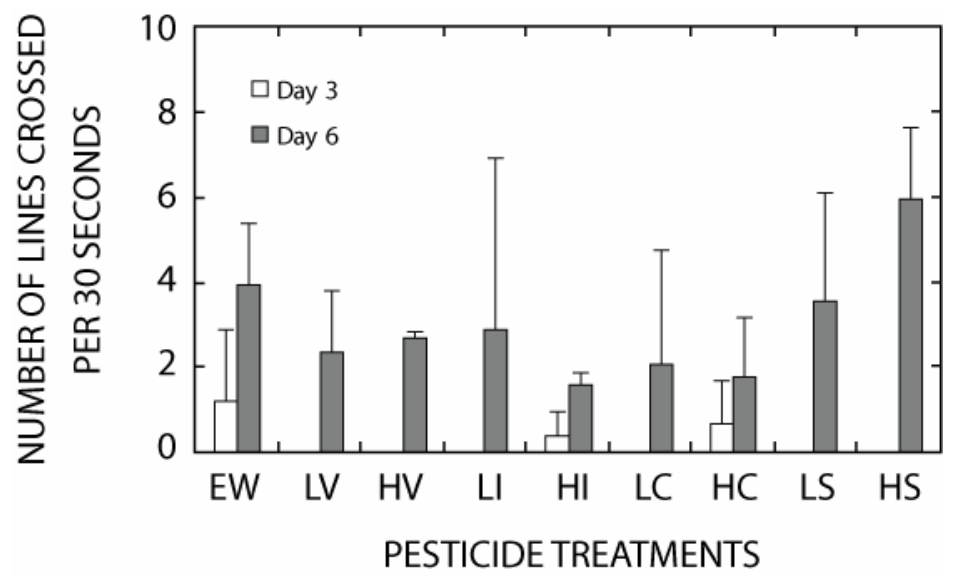

Figure 4. Preliminary data on single pesticide exposure effects on spontaneous swimming in zebrafish exposed from fertilization through swim-up. Bars represent means \pm SD for $n=2$ replicates of 5 larvae per replicate. Swimming measured on Days 3 and 6 post-fertilization. EW=Egg Water, $\mathrm{V}=$ Velpar $^{\mathrm{TM}}, \mathrm{I}=\operatorname{Imidan}^{\mathrm{TM}}, \mathrm{C}=$ Callisto $^{\mathrm{TM}}, \mathrm{S}=$ SpinTor $^{\mathrm{TM}}$. Doses were 0.75 and 7.5 ppb for Low and High, respectively. 


\section{Conclusions and Additional Research}

The long-term goal of our work is to provide risk assessors, blueberry growers, and restoration managers with data to aid in making science-based decisions regarding blueberry pesticide Best Management Practices in Maine (University of Maine Cooperative Extension 2007). We have little to no information to determine whether pesticides that are commonly in use now and pesticides that generally have fewer environmental effects and might be available in the near future (1-2 years) have detrimental effects on fish early life stages.

Preliminary data from the physiological and behavioral assays indicate there are no effects of environmentally realistic, and 10 times as high, pesticide exposures, done singly or in binary mixtures, on developing zebrafish. These data are preliminary, and further replication of the assays described above is underway to assess their statistical significance.

Replication of these assays will increase the statistical power required to detect differences among treatments. These assay replications will be coupled with additional behavioral studies to assess the effects of these pesticides on the ability of larval zebrafish to capture prey, a sensitive assessment of performance fitness. We will continue to develop chemical protocols for analyzing aqueous solutions of the four pesticide formulations. These protocols will be used to measure the dosing concentrations at the start and end of the 5-d exposure periods. The results of these studies will be compared to published findings and the significance of these findings evaluated for the use of these pesticides in river systems that support developing fish.

The results of this research will provide the basis for more extensive studies on the sublethal effects of blueberry pesticides, alone and in environmentally relevant combinations, on resident fish species in the Down East rivers of Maine. The results of such studies could influence which pesticides are used in Maine, could indicate whether Best Management Practices for currently-used and proposed for use pesticides need to be refined to further reduce potential aquatic contamination, and would provide data regarding the potential effects on resident fish of candidate pesticides before these pesticides come into use.

\section{References Cited}

Dunier, M., 1996, Water pollution and immunosuppression of freshwater fish: Italian Journal of Zoology, v. 63, p. 303-309.

Galloway, B.J., Munkittrick, K.R., Currie, S., Gray, M.A., Curry, R.A., and Wood, C.S., 2003, Examination of the responses of slimy sculpin (Cottus cognatus) and white sucker (Catostomus commersoni) collected on the Saint John River (Canada) downstream of pulp mill, paper mill, and sewage discharges: Environmental Toxicology and Chemistry, v. 22, p. 2898-2907.

Hermann, A.C., Millard, P.J., Blake, S.L., and Kim, C.H., 2004, Development of a respiratory burst assay using zebrafish kidneys and embryos: Journal of Immunological Methods, v. 292, p. 119129.

Jackson, H.P., 2003, 2003 Drift study of two aerially applied blueberry pesticides: Augusta, Maine, Maine Board of Pesticide Control, 19 p.

Jackson, H.P., 2003, 2003 Drift study of two aerially applied blueberry pesticides: Augusta, Maine, Maine Board of Pesticide Control, 19 p.

Lawrence, A.J., and Hemingway, K.L., 2003, Effects of Pollution on Fish: Molecular Effects and Population Responses: U.K., Blackwell Publishing, 368 p.

Maine Atlantic Salmon Task Force, 1997, Atlantic Salmon conservation plan for seven Maine rivers: Maine Atlantic Salmon Task Force, March 1997, 434 p. 
National Research Council, 2004, Atlantic salmon in Maine: Washington D.C., National Academies Press, 275 p.

Rooney, A.A., Matulka, R.A., and Luebke, R.W., 2003, Developmental atrazine exposure suppresses immune function in male, but not female Sprague-Dawley rats: Toxicological Sciences, v. 76, p. 366-375.

Samson, J.C., Goodridge, R., Olobatuyi, F., and Weis, J.S., 2001, Delayed effects of embryonic exposure of zebrafish (Danio rerio) to methylmercury (MeHg): Aquatic Toxicology, v. 51, p. 369-376.

University of Maine, 2007, Zebrafish Facility: Accessed April 10, 2007, at URL http://www.umaine.edu/bmmb/zebrafish.htm

University of Maine Cooperative Extension, 2007, Wild blueberry: Accessed April 10, 2007, at URL http://www.wildblueberries.maine.edu/

Westerfield, M., 1993, The zebrafish book: Eugene, Oregon, University of Oregon Press: Accessed on April 11, 2007, at URL http://zfin.org/zf_info/zfbook/zfbk.html 